Research Article

\title{
Reassessment of dispensing pharmacy and animal experiments in undergraduate practical pharmacology curriculum: feedback from students
}

\author{
Satish GR, Laxminarayana Kamath*, Jayanthi C. R.
}

Department of Pharmacology, Bangalore Medical College and Research Institute, K. R. Road, Bangalore, Karnataka-560002, India

Received: 08 February 2016 Accepted: 09 March 2016

\section{*Correspondence to:}

Dr. Laxminarayana Kamath, Email: koteshwarkamath@ yahoo.com

Copyright: (C) the author(s), publisher and licensee Medip Academy. This is an openaccess article distributed under the terms of the Creative Commons Attribution NonCommercial License, which permits unrestricted noncommercial use, distribution, and reproduction in any medium, provided the original work is properly cited.

\begin{abstract}
Background: Dispensing pharmacy exercises and animal experiments are still being taught in medical colleges even though they are not relevant for clinical practice. One has to keep pace with ever changing needs of the students and changing trends. So this study is designed to know the perceptions and alternative suggestions of MBBS students regarding dispensing pharmacy and animal experiments and use them to improve teaching.

Methods: 177 MBBS students studying at Bangalore medical college who have completed their university examination in pharmacology subject were included in this questionnaire based study. The data was analysed using descriptive statistics.

Results: Majority of the students disfavoured dispensing pharmacy (82\%) and animal experiments $(73 \%)$ in undergraduate practical pharmacology. $78 \%$ of the students preferred computer assisted learning (CAL) as an alternative to animal experiments. Some of the clinical pharmacology exercises favoured by students, as an alternative to dispensing pharmacy were, drug station (clinical station) with real cases in hospital $(88 \%)$, module on various drug formulations $(74 \%)$, module on pharmacovigilance $(74 \%)$, problem based exercises $(73 \%)$, drug administration procedures (68\%), drug dosage calculations (68\%), pharmacoeconomic exercises $(66 \%)$, prescription writing and criticism of prescription $(62 \%)$, short term research project (44\%) and so on.

Conclusions: Computer assisted learning seems to be a better alternative to animal experiments. In the changing scenario, teaching clinical pharmacology should be focused rather than teaching dispensing pharmacy, which is obsolete.
\end{abstract}

Keywords: Students, Dispensing pharmacy, Animal experiments, CAL, Clinical pharmacology

\section{INTRODUCTION}

Teaching and learning are the two sides of a coin. Educators have to keep pace with the ever changing needs of the students and the changing trends. Revising a curriculum requires inputs from all stakeholders. In medical education, graduating medical students are important stakeholders who can provide valuable feedback on deficiencies in their training. ${ }^{1}$

Similar to other branches of medical sciences, pharmacology is an ever changing medical subject. In medical colleges, there is a need for a dynamic pharmacology curriculum to keep pace with the rapid changes and requirements of clinical practice. ${ }^{2,3}$ Even today, dispensing pharmacy and animal experiments constitute as practical exercises in pharmacology in many medical colleges in India. ${ }^{4}$ The UG medical students of All India Institute of Medical Science, New Delhi and JIPMER, Pondicherry protested against the out dated practical curriculum which was being followed at their institute. ${ }^{4,5}$ Practical training must be need-based and relevant. Teaching of dispensing pharmacy exercises is irrelevant for today's clinical practice. Also in the context of ethical issues, protests from animal rights organizations such as, CPCSEA \& PETA, MCI guidelines and Supreme Court ban on animal experiments there is an urgent need to rethink the alternatives to animal experiments. ${ }^{6-9}$

There have been very few studies that have tried to define the relevance of these experiments and the attitude of the 
medical students towards them. Keeping the above in mind we conducted this study to explore the opinions of undergraduate students regarding suggested changes in the practical pharmacology curriculum and to implement it for subsequent batch of students.

\section{METHODS}

The present study was conducted in July 2014 at the Department of Pharmacology of Bangalore Medical College and Research Institute, Bangalore, India. After approval from the Institutional Ethics Committee (IEC), a total of 150 MBBS students who have completed their university examination in pharmacology subject were included in this questionnaire-based study. An additional 27 students had shown interest to participate in the study. So, the total sample size was 177. All the students who participated in the study had exposure to computer simulated experiments (The Software used was EX PHARMA designed by Dr. Raveendran, JIPMER), dispensing pharmacy and clinical pharmacology exercises. A structured validated questionnaire (Appendix) was developed consisting of 10 questions having options and a space for suggestions/remarks.

The students were permitted to indicate more than one option for the questions asked. The questions explored various aspects of animal experiments and dispensing pharmacy exercises and also provided a platform for expressing views on alternatives. A brief explanation was given about the questionnaire before it was administered to students $(n=177)$. The students were asked to be truthful and unbiased in answering the questions. They were asked not to reveal their identities, to ensure freedom of expression. The data was analysed using descriptive statistics.

\section{RESULTS}

All the 177 students who enrolled in our study answered the questionnaire. An overwhelming majority of students disfavoured dispensing pharmacy $(145 / 177 ; 82 \%)$ and animal experiments $(129 / 177 ; 73 \%)$ in undergraduate practical pharmacology (Figure $1 \& 2$ ). The students felt that the dispensing pharmacy exercises were not useful for future clinical practice/patient care $(138 / 177 ; 78 \%)$, waste of expenditure as the prepared ointment/lotion/suspension was thrown away $(110 / 177 ; 62 \%)$, readymade preparations are available at pharmacy $(142 / 177 ; 80 \%)$ (Figure 3). Main reasons for not liking the animal experiments were, difficult/scary to handle animals $(117 / 177 ; 66 \%)$, not useful in future clinical practice/patient care $(110 / 177 ; 62 \%)$, pity on animal use/sacrifice $(83 / 177 ; 47 \%)$, unpredictability in getting results $(55 / 177 ; 31 \%)$ (Figure 4$)$. A few students were interested in dispensing pharmacy $(25 / 177 ; 14 \%)$ and animal experiments $(37 / 177 ; 21 \%)$ emphasizing the need which is shown in Figure 5 and 6.

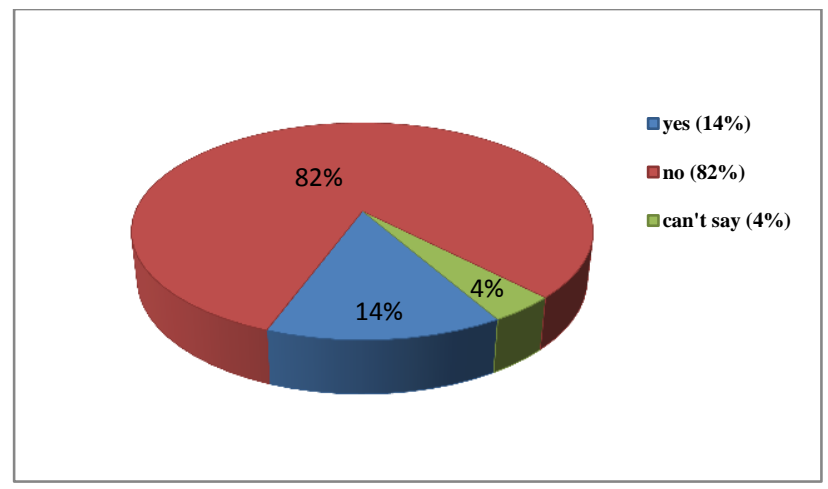

Figure 1: Percentage of students favoured dispensing pharmacy.

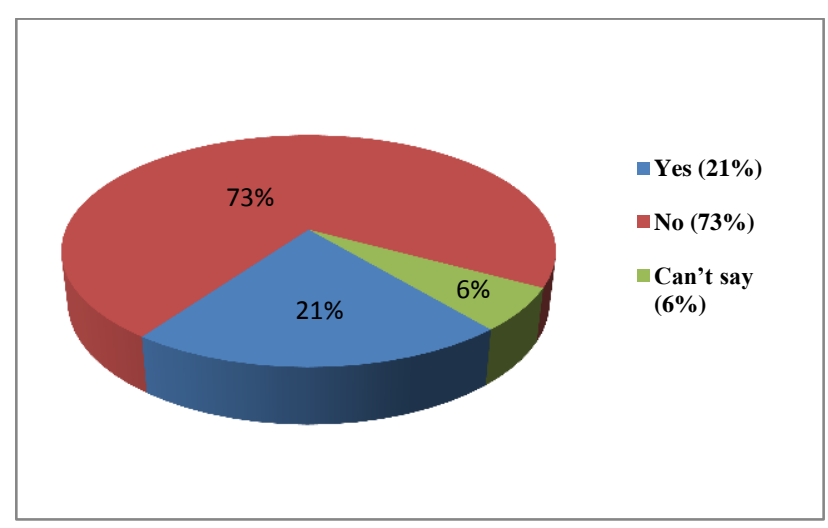

Figure 2: Percentage of students favoured animal experiments.

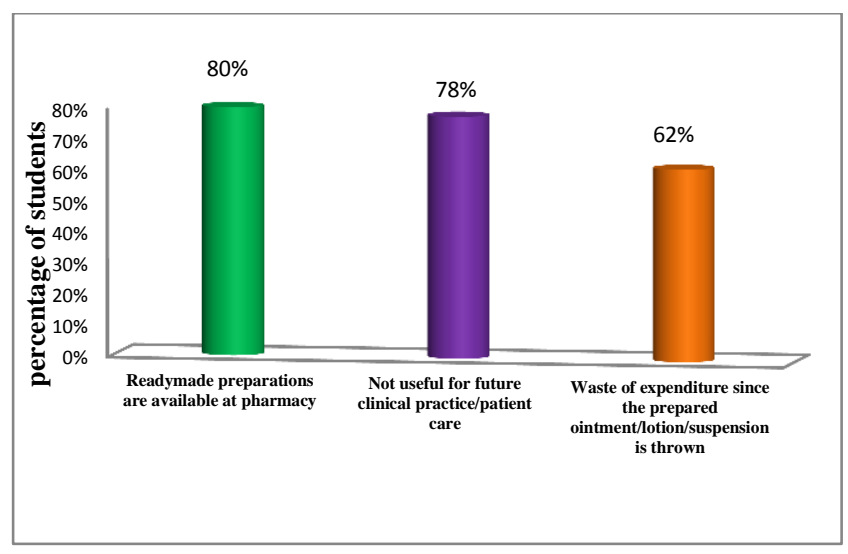

Figure 3: Reasons to dislike dispensing pharmacy.

Note: The total of percentages may not be 100 as students could choose multiple answers.

As alternatives to animal experiments, many suggestions were given which included; computer simulated animal experiments $(138 / 177 ; 78 \%)$ followed by pre-formed graphs/charts $(115 / 177 ; 65 \%)$, video films $(94 / 177 ; 53 \%)$, human volunteers $(27 / 177 ; 15 \%)$, experiments on culture tissue $(21 / 177 ; 12 \%)$, mannequin-based simulation $(14 / 177 ; 8 \%)$ (Figure 7). 


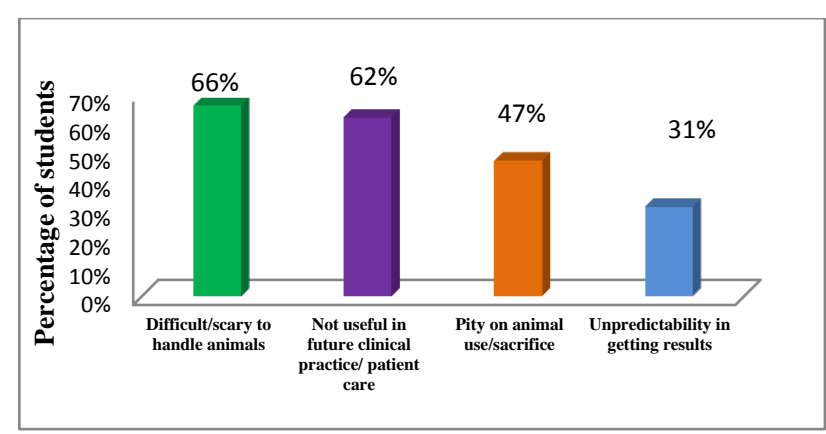

Figure 4: Reasons to dislike animal experiments.

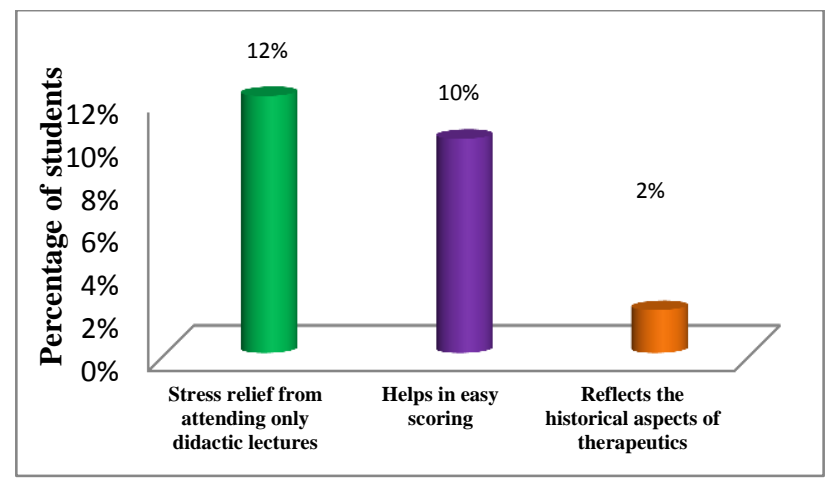

Figure 5: Reasons to like dispensing pharmacy.

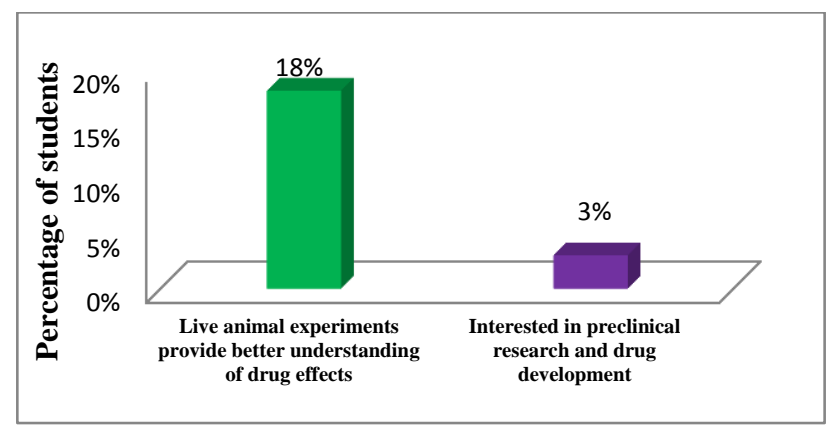

Figure 6: Reasons to like animal experiments.

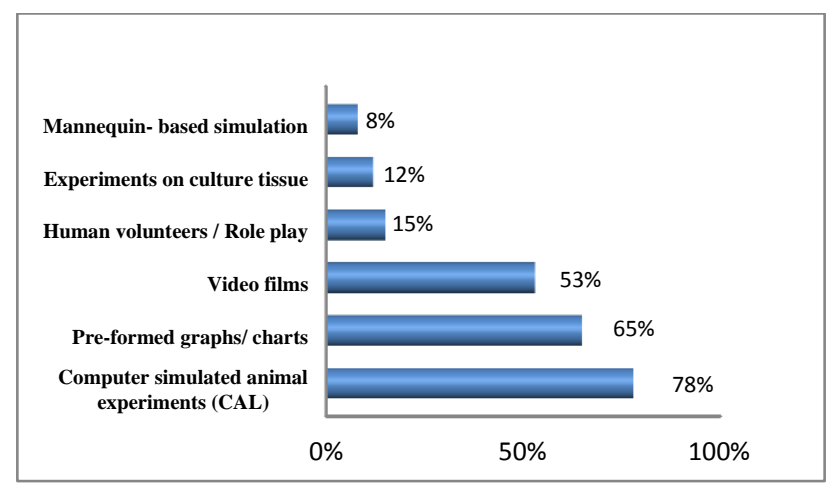

Figure 7: Alternatives suggested to animal experiments.

In our study, the students expressed their preference to CAL (computer simulated experiments) over animal experiments for the following reasons: it is more interesting and gives a better understanding of the topic $(122 / 177 ; 69 \%)$, saves time $(117 / 177 ; 66 \%)$, can be repeated $(115 / 177 ; 65 \%)$, effects of drugs can be clearly visualized $(113 / 177 ; 64 \%)$, errors in experiments can be reduced $(101 / 177 ; 57 \%)$, avoids ethical issues related to animal experiments $(96 / 177 ; 54 \%)$ (Table 1$)$.

\section{Table 1: Reasons to prefer CAL as an alternative to animal experiments.*}

\begin{tabular}{|llc|}
\hline Reasons & n & $\%$ \\
\hline $\begin{array}{l}\text { CAL is more interesting and gives a } \\
\text { better understanding of the topic than } \\
\text { animal experiments }\end{array}$ & 122 & $69 \%$ \\
\hline Computer simulations are time saving & 117 & $66 \%$ \\
\hline Can be repeated & 115 & $65 \%$ \\
\hline $\begin{array}{l}\text { Effects of drugs can be clearly } \\
\text { visualized by computer simulation }\end{array}$ & 113 & $64 \%$ \\
\hline $\begin{array}{l}\text { Errors in experiments can be reduced by } \\
\text { computer simulation }\end{array}$ & 101 & $57 \%$ \\
\hline $\begin{array}{l}\text { It avoids ethical issues related to animal } \\
\text { experiments }\end{array}$ & 96 & $54 \%$ \\
\hline
\end{tabular}

*Some students opted for more than one reason (multiple responses allowed).

Table 2: Various clinical pharmacology exercises as alternatives to dispensing pharmacy preferred by students.*

\begin{tabular}{|c|c|c|}
\hline Alternatives & $\mathbf{n}$ & $\%$ \\
\hline $\begin{array}{l}\text { Drug stations (clinical stations) with real } \\
\text { cases in hospital (most common cases such } \\
\text { as DM, HTN, Asthma etc.) }\end{array}$ & 156 & $88 \%$ \\
\hline Module on various drug formulations & 131 & $74 \%$ \\
\hline $\begin{array}{l}\text { Module on pharmacovigilance (Adverse } \\
\text { drug reaction monitoring) }\end{array}$ & 131 & $74 \%$ \\
\hline Problem based exercises & 129 & $73 \%$ \\
\hline $\begin{array}{l}\text { Module on essential medicine list, P-drug } \\
\text { concept, banned drugs }\end{array}$ & 126 & $71 \%$ \\
\hline $\begin{array}{l}\text { Module on drug usage in special situations } \\
\text { such as pediatrics, geriatrics, pregnancy and } \\
\text { lactation, liver and kidney dysfunctions } \\
\text { including drug dosage calculations }\end{array}$ & 120 & $68 \%$ \\
\hline $\begin{array}{l}\text { Module on drug administration procedures } \\
\text { and drug delivery devices. }\end{array}$ & 120 & $68 \%$ \\
\hline Module on pharmacoeconomics & 117 & $66 \%$ \\
\hline Module on emergency drugs & 112 & $63 \%$ \\
\hline $\begin{array}{l}\text { Prescription writing and criticism of } \\
\text { prescription }\end{array}$ & 110 & $62 \%$ \\
\hline Fixed dose drug combination & 108 & $61 \%$ \\
\hline $\begin{array}{l}\text { Critical appraisal of drug promotional } \\
\text { literature }\end{array}$ & 96 & $54 \%$ \\
\hline $\begin{array}{l}\text { Short term research projects (protocol } \\
\text { writing) in pharmacology }\end{array}$ & 78 & $44 \%$ \\
\hline
\end{tabular}

Various clinical pharmacology and therapeutic exercises as an alternative to dispensing pharmacy preferred by students were drug stations (clinical stations) with real 
cases $(156 / 177 ; 88 \%)$, module on various drug formulations $(131 / 177 ; 74 \%)$, module on pharmacovigilance $(131 / 177 ; 74 \%)$, problem based exercises (129/177;73\%) and drug administration $(120 / 177 ; 68 \%)$, prescription writing and criticism of prescription (110/177;62\%) etc. (Table 2).

A large number of students $(166 / 177 ; 94 \%)$ felt that regular feedback from students is necessary to improve the teaching.

\section{DISCUSSION}

The enthusiasm shown by the students to participate in the study clearly indicates the need to change practical pharmacology curriculum. Not surprisingly, a significant proportion of students disfavoured dispensing pharmacy and animal experiments quoting that they were not useful for future clinical practice. Our findings correlate with similar studies done by Vasundara K et al, ${ }^{9}$ Saurabh MK et al. ${ }^{4}$ Practicing doctors need not know animal handling skills and the intricacies of drug manufacture as readymade preparations are available. So, authors are of the opinion that these can be deleted from the curriculum with better alternatives.

In our analysis of the feedback, majority of the students felt the need of alternatives such as, computer simulations (CAL), preformed graphs, video films, human volunteers, and mannequin-based simulation, to the use of live animals. These results are seconded by various studies. ${ }^{10-}$ 12 Several states of the USA and Europe have passed "choice in dissection" laws, which provide a choice to the student to use alternatives to dissection. Several medical schools in the USA, such as Mayo, Harvard, Columbia and Yale now have no live animal laboratories. The MCI amendment in 2009 also suggested all medical colleges to use alternatives to animal experiments in the undergraduate medical course. ${ }^{6,8,12}$

In our study, three fourths of the students supported CAL as an alternative to animal experiments. It is worth noting that a large number of students expressed the advantages of CAL such as reduction in animal use, saves time, clear estimation of drug effects, repeated observation of difficult experiments and minimum errors. Our study findings were endorsed by other similar wellexecuted studies which also have highlighted the usefulness of CAL. ${ }^{4,13-15}$ In a study by Tikoo D et al, majority of the students $(89 \%)$ felt that CAL should become a part of regular experimental pharmacology teaching. ${ }^{14}$ A survey by Geetanjali found that EX PHARMA instituted by JIPMER was widely accepted by many other colleges in India. ${ }^{5}$ EX PHARMA pro is an educational software package which simulates animal experiments to help students remember, understand and recall drug actions. The proposed new curriculum of MCI "vision-2015" for undergraduates might make it mandatory to have simulation labs as an alternative. ${ }^{16}$ According to author's opinion, by introducing CAL, understanding of pharmacology can be achieved without the existing set of animal experiment exercises. CAL will reduce the total investment, space, equipment, animals and faculty time.

Some of the innovative clinical pharmacology and therapeutic exercises suggested by students as alternatives to dispensing pharmacy are discussed below. Our study revealed that $88 \%$ of students prefer drug stations (clinical stations) with real case scenario as an alternative. Similar views have been expressed in the following studies. A study by Saurabh MK et al, found out that $81 \%$ of the students opted for case studies and treatment protocols to be added as a part of practical pharmacology. ${ }^{4}$ In another study by Vasundara K et al, ${ }^{9}$ $93 \%$ of the students were of the opinion that real patient based learning of pharmacology was felt to be more relevant in the present scenario. ${ }^{9}$ Tikoo $\mathrm{D}$ et al, revealed that majority of the students $(61 \%)$ wanted clinical case studies to be incorporated in the routine teaching of pharmacology for better understanding and better correlation of drugs used in diseases. ${ }^{1}$ Case-based learning has been shown to be effective for medical programs in the U.S., Europe, and South America. ${ }^{17,18}$ The authors are of the opinion that inviting patients to practical classes motivates students. The real cases integrate their knowledge of pharmacology with clinical scenarios which will improve their prescribing skills and help in better management of patients.

Majority of the students in the survey insisted to include pharmacovigilance module in practical classes. An interesting finding in a study by Tabassum $\mathrm{R}$ et al, was that $79.8 \%$ students opined that they have not been trained on how to report ADR; $54.4 \%$ cited that topic of pharmacovigilance is not well covered. ${ }^{19}$ In a study by Vasundara $\mathrm{K}$ et al, found that $95 \%$ of the students expressed the need to be sensitized about pharmacovigilance. ${ }^{9}$ Authors suggest that medical students should be taught pharmacovigilance, importance of ADR monitoring and reporting. An assignment can be given to students to report adverse drug reaction.

In our study, $62 \%$ of the students preferred prescription writing and critical evaluation of prescription. Going through the literature, in a study conducted on foundation-year doctors in UK, it was found that only $32 \%$ respondents considered themselves "competent to prescribe" at the time of graduation. ${ }^{20}$ In another study by Nitya $S$ et al revealed that $67 \%$ of participants had encountered problem while prescribing the drugs during their internship. ${ }^{21}$ Prescribing drugs is an essential and an integral part of any medical treatment. More emphasis should be given while prescribing for children, elderly, pregnant women and people with impaired renal or liver functions. The factual burden posed by the increasing number of prescription drugs should be eased by prioritized learning around essential drug list and preparing a priority drug list. 
$66 \%$ of the students in our study were interested in having pharmacoeconomic module. One of the important factors for poor patient compliance was the high cost of drugs, especially for chronic diseases. A module on essential drug list, rational drug use, $\mathrm{P}$ drug concept, cost variation analysis of different brands; sensitize them to choose the drugs based on efficacy, safety, suitability, and cost. Also amalgamation of practical exercises on drug administration procedures (i.e. setting up of I.V. drip for the infusion of quinine, dopamine, oxytocin, aminophylline and nebulization procedure in bronchial asthma), dosage calculations, critical evaluation of drug promotional literature, drug formulations are needed to improve clinical pharmacology skills. Many medical schools in developed countries incorporated Clinical pharmacology and therapeutics (CPT) into curricula as a distinct course. ${ }^{3}$ CPT is a best addition to the armamentarium of pharmacology teaching tools which can be introduced without much investment.

\section{CONCLUSION}

Keeping the results of the survey, protests by animal rights organizations like PETA, CPCSEA, supreme court restrictions on animal experiments; computer assisted learning (CAL) seems to be a better alternative to animal experiments to fulfil the learning needs of UG medical students.

In the changing scenario to produce doctors with the capability of providing quality health care to the population and to make them a strong pillar of health care delivery system, clinical pharmacology teaching should be focused rather than teaching dispensing pharmacy which is obsolete.

However a uniform teaching program for practical pharmacology does not exist in medical colleges in India and the confusion between the conventional and contemporary still prevails. In this context it is better to have a unique practical syllabus for all medical colleges in India by consulting all stakeholders involved with pharmacology.

\section{ACKNOWLEDGEMENTS}

We acknowledge $2^{\text {nd }}$ MBBS students for their participation in the survey. The authors express their heartfelt gratitude to the departmental colleagues for their cooperation. We are also thankful to Dr. Raveendran and his team for providing free version of EX-PHARM software.

\section{Funding: No funding sources}

Conflict of interest: None declared

Ethical approval: The study was approved by the Institutional Ethics Committee

\section{REFERENCES}

1. Tikoo D, Gupta M, Geeta S. Student feedback on teaching-learning methodology and evaluation methods in pharmacology. Int $\mathrm{J}$ Basic Clin Pharmacol. 2015;4:1260-6.

2. Hughes I. 20/20 vision-teaching pharmacology in 2020 new knowledge, skills, tools and attitudes. Available www.socesfar.com/attachments/article/106/2009.pdf Accessed on 20 January, 2016.

3. Maxwell S, Walley T. Teaching safe and effective prescribing in UK medical schools: a core curriculum for tomorrow's doctors. $\mathrm{Br} \mathrm{J}$ Clin Pharmacol. 2003;55(6):496-503.

4. Saurabh MK, Agrawal J. The opinion of undergraduate medical students on current curriculum and teaching methodology of pharmacology in four medical colleges of India: a questionnaire based study. Int $\mathbf{J}$ Basic Clin Pharmacol. 2015;4:970-5.

5. Raveendran R, Batmanabane G. Alternatives to animals in teaching: experience in an Indian medical school. In proceedings of the ALTEX $8^{\text {th }}$ World Congress, Montreal 2011 (Vol. 206). Available at: www.altex.ch/resources/355360Raveendran31.pdf. Accessed on 20 January, 2016.

6. Medical council of India, New Delhi, amendment notification of 8 July 2009 to the minimal standard requirements for medical colleges with 150 admissions annually, regulations, 1999. Available at: http://www.mciindia.org/helpdesk/how_to_start/ST ANDARD\%20FOR\%20150.pdf. Accessed on 20 January, 2016.

7. Committee for the purpose of control and supervision of experiments on animals (CPCSEA). Available http://moef.nic.in/modules/divisions/cpcsea/. Accessed on 20 January, 2016.

8. Badyal DK, Desai C. Animal use in pharmacology education and research: The changing scenario. Indian J Pharmacol. 2014;46(3):257-65.

9. Vasundara K, Pundarikaksha HP, Vijendra R, Girish K, Jyothi R, Srinivasa P. Existing and expected practical medical pharmacology curriculum - A survey. J Clin Diagnostic Res. 2011;5(2):340-3.

10. Seropian M, Dillman D, Lasater K, Gavilanes J. Mannequin-based simulation to reinforce pharmacology concepts. Simul Healthc. 2007;2(4):218-23.

11. Tembhurne SV, Sakarkar DM. Alternative to use of live animal in teaching pharmacology and physiology in pharmacy undergraduate curriculum: an assessment of 120 students' views. Int J Med Pharm Sci. 2011;1(1):4-7.

12. Babu CS, Latha K, Thirunavukkarasu J, Tharani CB. Pharmacology virtual experimental pharmacology an alternative or not?-a global assessment by pharmacology faculties and MBBS students. Rec Res Sci Tech. 2011;3(10):25-9. 
13. Nettath S. Computer assisted learning (CAL) as a teaching learning method in teaching experimental pharmacology. Int $\mathbf{J}$ Basic Clin Pharmacol. 2014;3:63-5.

14. Tikoo D, Gupta M. Student's perception and experience of computer assisted learning as a teaching method in experimental pharmacology. Int J Basic Clin Pharmacol. 2015;4:1168-74.

15. Dhingra MS, Singh A, Singh J. Animal experiments and pharmacology teaching at medical schools in India: a student's eye view. AATEX. 2006;11(3):185-91.

16. Vision 2015, Medical Council of India Available from:

http://www.mciindia.org/tools/announcement/MCI_ booklet.pdf. Accessed on 16 January, 2016.

17. Blewett EL, Kisamore JL. Evaluation of an interactive, case-based review session in teaching medical microbiology. BMC Med Educ. 2009;9:56.
18. Hughes I. Teaching pharmacology in 2010 - new knowledge, new tools, new attitudes. Nihon Yakurigaku Zasshi. 2003;122(5):411-8.

19. Tabassum R, Bhat MY, Farhat S. A descriptive study of knowledge of Pharmacovigilance and adverse drug reactions among second professional undergraduate medical students in a teaching hospital. Intern J Basic Clin Pharmacol. 2015;4(5):1016-20.

20. Han WH, Maxwell SR. Are medical students adequately trained to prescribe at the point of graduation? Views of first year foundation doctors. Scott Med J. 2006;51(4):27-32.

21. Nitya S, Mangaiarkkarasi A, Ali RM, Sawadkar MS. Intern's knowledge of clinical pharmacology and therapeutics at Puducherry: a cross-sectional study. Int J Basic Clin Pharmacol. 2013;2:622-8.

Cite this article as: Satish GR, Laxminarayana K, Jayanthi CR. Reassessment of dispensing pharmacy and animal experiments in undergraduate practical pharmacology curriculum: feedback from students. Int J Basic Clin Pharmacol 2016;5:285-92. 


\section{Appendix: Questionnaire}

\section{Reassessment of dispensing pharmacy and animal experiments in undergraduate practical pharmacology curriculum: feedback from students}

\section{INSTRUCTIONS:}

1. Please do not sign/write your name

2. Please answer all questions

3. You may tick off more than one answer to a question (except for questions $1,4 \& 10$ )

4. You can give your additional suggestions/ remarks/reasons to any question

5. Feedback obtained will be used to improve pharmacology teaching for subsequent batches.

1. Do you favour the dispensing pharmacy exercises in practical pharmacology?
a) Yes
b) No
c) Can't say

2. If yes, reasons for liking pharmacy practical classes
a) Stress relief from attending didactic lectures
b) Helps in easy scoring
c) Reflects the historical aspects of therapeutics

3. If no, reasons for not liking pharmacy practical classes
a) Not useful for future clinical practice/patient care
b) Waste of expenditure as the prepared ointment/lotion/suspension is thrown
c) Readymade preparations available at pharmacy

4. Do you favour animal experiments in practical pharmacology?
a) Yes
b) No
c) Can't say

5. If yes, reasons to like animal experiments in practical pharmacology

a) Live animal experiments provide better understanding of drug effects

b) Interested in preclinical research and drug development

6. If no, reasons to dislike animal experiments in practical pharmacology
a) Difficult/scary to handle animals
b) Pity on animal use/sacrifice
c) Not useful in future clinical practice/patient care
d) Unpredictability in getting results

7. According to recent guidelines the animal studies in medical colleges are banned. What better alternatives you suggest among the following:
a) Computer simulated animal experiments
b) Video films
c) Human volunteers/role play
d) Mannequin-based simulation
e) Pre-formed graphs/charts
f) Experiments on culture tissue

8. The reasons to prefer CAL over animal experiments are following:
a) CAL is more interesting and gives a better understanding of the topic than animal experiments
b) Effects of drugs can be clearly visualized by computer simulation
c) Errors in experiments can be reduced by computer simulation
d) Computer simulations are time saving
e) Can be repeated
f) Avoids ethical issues related to animal experiments

9. I prefer the following modules on clinical pharmacology and therapeutics as an alternatives to dispensing pharmacy exercises so that it helps in future clinical practice/patient care
a) Drug stations (clinical stations) with real cases in hospital (commonest cases such as DM, HTN, Asthma etc)
b) Problem based exercises
c) Prescription writing and criticism of prescription
d) Module on drug usage in special situations such as pediatrics, geriatrics, pregnancy and lactation, liver and kidney dysfunctions including drug dosage calculations
e) Module on various drug formulations 
f) Module on drug administration procedures and drug delivery devices

g) Module on emergency drugs

h) Fixed dose drug combination

i) Module on essential medicine list, P-drug concept, banned drugs

j) Module on pharmacovigilance (Adverse drug reaction monitoring)

k) Module on pharmacoeconomics

1) Critical appraisal of drug promotional literature

m) Short term research projects (protocol writing) in pharmacology

10. Do you feel regular feedback from students is necessary/important to improve the teaching:

a) Yes

b) $\mathrm{No}$

c) Can't say 